ANUVA Volume 2 (2): 225-231, 2018

Copyright (C2018, ISSN: 2598-3040 online

Available Online at: http://ejournal.undip.ac.id/index.php/anuva

\title{
Aspek Pendidikan Nyanyian Kelonan
}

\author{
Rukiyah $^{\left.1^{*}\right)}$ \\ Program Studi Bahasa dan Sastra Indonesia, Fakultas Ilmu Budaya, Universitas Diponegoro, \\ Jl. Prof. Soedarto, SH, Kampus Undip Tembalang, Semarang, Indonesia \\ *) Korespondensi:rukiyah50@yahoo.com
}

\begin{abstract}
The goal to be achieved in this research is to describe the education aspect of kelonan song. The method used, namely literature study and content analysis. The results of the discussion show that the tradition of singing kelonan songs as cultural heritage of ancestors need to be preserved because the singing kelonan rhythmic smooth and calm is suitable for use as a medium to put the child to sleep. In addition to functioning as a child's bedtime singing kelonan has another function, namely as a means of education because the lyrics of songs kelnyan songs mostly contains prayers and advice. Educational aspects contained in the three songs kelonan used in this study are: 1) the teachings to always pray to God Almighty, 2) the teachings of character, and 3) love the homeland and nation.
\end{abstract}

Keywords: kelonan song; content analysis; education aspect

\begin{abstract}
Abstrak
Tujuan yang ingin dicapai dalam penelitian ini adalah mendeskripsikan aspek pendidikan lagu kelonan. Metode yang digunakan, yaitu studi pustaka dan analisis isi. Hasil pembahasan menunjukkan bahwa tradisi menyanyikan lagu kelonan sebagai warisan budaya nenek moyang perlu dilestarikan karena nyanyian kelonan yang berirama halus dan tenang sangat cocok dipakai sebagai media untuk menidurkan anak. Selain berfungsi sebagai pengantar tidur anak nyanyian kelonan mempunyai fungsi yang lain, yaitu sebagai sarana pendidikan karena lirik lagu-lagu nyanyian kelonan kebanyakan berisi doa dan nasihat. Aspek pendidikan yang terdapat dalam ketiga lagu kelonan yang digunakan dalam penelitian ini adalah: 1) ajaran agar selalau berdoa kepada Tuhan Yang Maha Esa, 2) ajaran budi pekerti, dan 3) cinta pada tanah air dan bangsa.
\end{abstract}

Kata kunci: nyanyian kelonan; analisis isi; aspek pendidikan

\section{Pendahuluan}

Nyanyian kelonan (lullaby) adalah nyanyian yang mempunyai lagu dan irama yang halus dan tenang sehingga dapat menimbulkan rasa kantuk yang mendengarnya. Nyanyian ini disenandungkan untuk menidurkan bayi atau balita. Pada masa lalu seorang ibu atau ayah saat menidurkan bayi atau balitanya mengoyang-goyang bayinya yang diletakkan pada ayunan yang terbuat dari selendang atau menggendongnya sambil menyanyikan lagu. Seorang anak akan merasa nyaman mendengar senandung ibu atau ayahnya sehingga mereka tertidur. Nyanyian kelonan yang mempunyai lagu dan irama yang halus dan tenang, berulang-ulang, ditambah dengan kata-kata kasih sayang dapat membangkitkan kedekatan orang tua dengan anak. 
Dewasa ini orang tua cenderung lebih senang mengasuh anaknya menggunakan media elektronik, seperti televisi atau gawai sehingga lagu kelonan jarang didendangkan bahkan kemungkinan orang tua sekarang sudah tidak mengenal lagi lagu kelonan. Jika hal ini terus berlanjut kemungkinan besar lagu kelonan akan menghilang. Sangat disayangkan jika hal ini benar terjadi mengingat tradisi menyanyikan lagu kelonan selain dapat menumbuhkan kedekatan orang tua dengan anak juga dapat dipakai sebagai sarana pendidikan. Pendidikan anak sudah dimulai pada saat anak dalam kandungan seorang ibu. Beberapa penelitian menunjukkan bahwa salah satu cara mendidik anak dalam kandungan adalah dengan memperdengarkan musik klasik pada janin. Hal ini dipercaya dapat menambah kecerdasan pada anak. Jika melalui pendengaran dapat mempengaruhi perkembangan anak, maka saat bayi telah lahir tentunya dapat pula dipengaruhi dengan lagu kelonan yang dinyanyikan orang tuanya. Syair-syair lagu kelonan mempunyai nilai-nilai pendidikan yang tentunya akan membekas pada pikiran anak karena di usia balita apa yang mereka dengar dan lihat akan tersimpan dalam pikirannya.

Berdasarkan uraian tersebut di atas pada tulisan ini penulis akan membahas aspek pendidikan dalam lagu kelonan. Adapun masalah yang akan diteliti adalah aspek pendidikan apa saja yang terdapat lagu kelonan? Bertolak dari rumusan masalah tersebut tujuan yang akan dicapai adalah untuk mendeskripsikan aspek pendidikan lagu kelonan. Dalam hal ini penulis hanya membahas tiga lagu kelonan, yaitu: "Lelo Ledhung", "Belaian Sayang", dan "Timang-timang Anakku Sayang".

\section{Landasan Teori}

\subsection{Nyanyian Kelonan}

Nyanyian kelonan (lullaby) merupakan salah satu bentuk nyanyian rakyat. Nyanyian rakyat adalah salah satu bentuk folklor yang terdiri dari kata-kata dan lagu yang beredar secara lisan di antara anggota kolektif tertentu, berbentuk tradisional, serta mempunyai banyak varian (Brunvand melalui Danandjaya, 1994:141). Nyanyian rakyat dibedakan menjadi dua yaitu nyanyian rakyat yang tidak sesungguhnya dan nyanyian rakyat yang sesungguhnya. Nyanyian rakyat yang tidak sesungguhnya adalah nyanyian rakyat yang mementingkan salah satu unsur, yaitu lagu atau lirik. Nyanyian rakyat yang mementingkan lagu oleh Brunvand disebut dengan proto folksong atau nyanyian rakyat yang bersifat permulaan. (Brunvand melalui Danandjaya, 1994:145). Proto folksong dibedakan menjadi wordless folksong dan near song. Wordless folksong adalah nyanyian rakyat tanpa kata-kata, suara penyanyinya hanya menirukan suara alat musik tertentu, kalupun ada kata-kata biasanya tidak bermakna apa-apa. Sebagai contoh adalah nyanyian yang dipergunakan untuk mengiringi Tari Kecak di Bali. Jenis kedua adalah nyanyian rakyat yang disebut Brunvand near song, yaitu nyanyian rakyat yang lebih mementingkan lirik dari pada lagu (Brunvand dalam Danandjaya, 1994:146). Contoh near song seruan pedagang keliling yang menawarkan dagangannya. 
Nyanyian rakyat yang sesungguhnya adalah nyanyian rakyat yang antara lagu dan lirik sama pentingnya. Yang termasuk ke dalam golongan nyanyian rakyat yang sesungguhnya adalah: 1) nyanyian rakyat yang berfungsi, 2) nyanyian rakyat yang bersifat liris, dan 3) nyanyian rakyat yang bersifat berkisah. Nyanyian rakyat yang berfungsi adalah nyanyian rakyat yang lirik maupun lagunya cocok dengan irama aktivitas khusus dalam kehidupan manusia. Nyanyian rakyat yang berfungsi dibedakan menjadi tiga subkategori, yaitu nyanyian kelonan, nyanyian kerja dan nyanyian permainan. Nyanyian rakyat yang bersifat liris adalah nyanyian rakyat yang teksnya bersifat liris, yang merupakan pencetusan rasa haru pengarangnya. Nyanyian rakyat liri dibedakan menjadi nyanyian liris yang sesungguhnya dan nyanyian liris yang tidak sesungguhnya. Adapun nyanyian rakyat yang bersifat berkisah adalah nyanyian rakyat yang menceriterakan suatu kisah. Nyanyian rakyat yang termasuk dalam kategori ini adalah balada dan epos (Danandjaya, 1994:146-152)

\subsection{Pendidikan}

Pendidikan adalah usaha mengubah tingkah laku individu dalam kehidupan pribadinya sebagai bagian dari kehidupan masyarakat dan kehidupan alam sekitarnya (Al-Syaibani, 1979:399). Dengan pendidikan, orang akan mengetahui pa yang benar dan apa yang tidak benar, apa yang baik dan apa yang tidak baik, apa yang patut dan apa yang tidak patut (Rapar, 1988:110). Peranan pendidikan yang paling utama bagi manusia adalah mengubah dan memperbarui. Perubahan dan pembaruan akan membentuk manusia utuh, yaitu manusia yang berhasil menggapai segala keutamaan dan moralitas jiwa yang mengantarkannya kepada kebaikan dan keadilan (Jalaluddin dan Abdullah, 2007:79). Dengan demikian dapat dikatakan bahwa tingkah laku dan karakteristik manusia sangat ditentukan oleh pendidikan. Hubungan antara pendidikan dan kehidupan manusia ibarat dua sisi mata uang yang tidak dapat dipisahkan.

Menurut Syam (melalui Jalaluddin dan Abdullah, 2007:138), pendidikan secara praktis tidak dapat dipisahkan dengan nilai-nilai, terutama yang meliputi kualitas kecerdasan, nilai ilmiah, nilai moral, dan nilai agama. Moral dan agama menurut Muslich (2006: 5-7) merupakan pondasi yang kuat dalam membangun kehidupan bertaqwa kepada Allah swt. untuk menuju kepada pembangunan manusia seutuhnya lahir batin.

\section{Metode Penelitian}

Penelitian ini merupakan penelitian kualitatif, yaitu penelitian yang menghasilkan data deskriptif berupa kata-kata. Menurut Sukmadinata (2005:60) penelitin kualitatif adalah suatu penelitian yang ditujukan untuk mendeskripsikan dan menganalisis fenomena, peristiwa, aktivitas sosial, sikap, kepercayaan, persepsi pemikiran orang secara individual maupun kelompok. Tahap pengumpulan data dalam penelitian ini menggunakan studi pustaka dengan teknik pembacaan dan pencatatan. Penerapan metode dan teknik ini bertujuan untuk mengumpulkan nyanyian kelonan yang dijadikan objek penelitian. 
Penelitian ini bertujuan untuk mengungkap aspek pendidikan dalam lagu kelonan untuk itu diperggunakan metode analisis isi. Menurut Berelson metode analisis isi adalah teknik penelitian yang objektif, sistematis, dan deskriptif kuantitatif tentang isi dari wujud komunikasi. Lebih lanjut dijelaskan bahwa metode analisis isi erat berkaitn dengan proses dan isi komunikasi. Proses komunikasi mencakup unsur siapa, apa, kepada siapa, bagaimana pesan tersebut disampaikan, dan bagaimana pengaruh yang ditimbulkannya. Isi komunikasi tmencakup unsur isi yang terwujud dan isi yang tersembunyi. (Berelson melali Waluyo, dkk. 1988)

Metode analisis isi dipergunakan untuk menganalisis isi lagu kelonan untuk mengungkap aspek pendidikan yang terdapat di dalamnya. Dalam hal ini dipergunakan pendekatan pragmatik, yaitu suatu pendekatan yang menitik beratkan pembaca. (Abrams dalam Teeuw, 1984:50). Lebih lanjut Teeuw menjelaskan bahwa istilah pragmatik menunjuk pada efek komunikasi yang seringkali dirumuskan dalam istilah Horatis: seniman bertugas untuk memberi ajaran dan kenikmatan. Seni harus menggabungkan sifat utile dan dulce, bermanfaat dan menyenangkan. Suatu karya haruslah dapat menghibur dan bermanfaat bagi pembacanya. (Teeuw, 1984:51). Dengan demikian dapat dikatakan bahwa pendekatan pragmatik adalah pendekatan yang menekankan fungsi nilai-nilai dalam karya seni sehingga pembaca dapat mengambil manfaat yang ada di dalamnya.

\section{Pembahasan}

Ada banyak lagu kelonan yang biasa dinyanyikan seorang ibu/ayah untuk menidurkan anaknya, baik menggunakan bahasa Indonesia/Melayu seperti "Nina Bobo", "Timang-Timang Anakku Sayang", "Belaian Sayang", dan "Tidurlan Intan" maupun lagu-lagu yang menggunakan bahasa daerah, misalnya "Lelo Ledhung", "Beber-beber Hiding Aing", "Modom", "Dodoi", "Owa-Owa", dan Doda Idi Damee". Lagu kelonan liriknya penuh makna dan doa orang tua untuk anaknya. Dari berbagai lagu kelonan di atas dalam tulisan ini penulis hanya akan membahas tiga lagu, yaitu "Lelo Ledhung”, "Belaian Sayang”, dan “Timang-Timang Anakku Sayang".

\subsection{L agu “ Lelo Ledhung”}

Tak lelo lelo lelo ledhung

Cup menenga aja pijer nangis (Diamlah jangan terus menangis)

Anakku sing ayu/bagus rupane (Anakku yang cantik/tampan parasnya)

Yen nangis ndak ilang ayune/baguse (Kalau menangis akan hilang cantiknya/tampannya)

Tak gadang bisa urip mulyo (Ku harap dapat hidup serba kecukupan dan bahagia)

Dadiyo wanita/priya kang utomo (jadilah wanita/pria yang utama)

Ngluhurke asmane wong tuwo (menjaga kehormatan nama orang tuwa)

Dadiyo pandekaring bangsa (jadilah pendekar bangsa) 
Wis cup menenga anakku (Sudah diamlah anakku)

Kae mbulane ndadari (Lihat bulannya bulat)

Kaya butho nggegilani (Seperti raksasa menakutkan)

Lagi ngoleki cah nangis (Sedang mencari anak yang menangis)

Tak lelo lelo lelo ledhung

Enggal menengga ya cah ayu/bagus (Cepatlah diam anak cantik/tampan)

Tak emban slendang batik kawung (Saya gendhong dengan selendang batik kawung)

Yen nangis mundhak ibu bingung (kalau menangis membuat ibu bingung)

Lirik lagu di atas penuh dengan doa dan harapan hal ini tersurat pada bait kedua sebagai berikut

Tak gadang bisa urip mulyo (Ku harap dapat hidup serba kecukupan dan bahagia)

Dadiyo wanita/priya kang utomo (jadilah wanita/pria yang utama)

Ngluhurke asmane wong tuwo (menjaga kehormatan nama orang tuwa)

Dadiyo pandekaring bangsa (jadilah pendekar bangsa)

Pada lirik lagu bait kedua di atas orang tua berharap anaknya kelak dapat hidup berkecukupan tak kurang suatu apa pun dan berbahagia serta menjadi seorang wanita/pria yang terpandang yang dapat mengharumkan nama orang tua sebagai pahlawan bangsa.

Selain berisi doa lirik lagu "Lelo Ledhung" juga mengandung ajaran bahwa setelah dewasa anak hendaknya dapat menjaga nama baik orang tua dan mengharumkan nama orang tuanya " dengan jalan menjadi wanita/pria yang dapat menjadi panutan bagi masyarakat dan menjadi orang yang berguna bagi bangsa. Dengan kata lain dapat dikatakan bahwa lagu kelonan "Lelo Ledhung" mengandung ajaran budi pekerti serta rasa cinta pada bangsa Indonesia.

\subsection{L agu “Belaian Sayang"}

Waktu hujan turun, rintik perlahan

Bintang pun menyepi, awan menebal

Ku timang si buyung belaian sayang

Anakku seorang, tidurlah tidur

Ibu mendoa, ayah menjaga

Agar kau kelak jujur melangkah

Jangan engkau lupa, tanah pusaka

Tanah air kita Indonesia

Pesan yang disampaikan dalam lagu "Belaian Sayang" karya Bing Slamet adalah harapan orang tua agar anaknya kelak jujur dalam melangkah, apa pun yang dilakukannya selalu dilandasi dengan kejujuran 
untuk itulah ibu dan ayahnya selalu berdoa untuk sang anak. Lagu ini juga mengandung pesan agar si anak cinta pada tanah air Indonesia, jaganlah melupakan tanah air tercinta Indonesia karena di sanalah dia dilahirkan, menghirup udara, minum, dan makan dari bumi Indonesia tercinta. Hal ini terdapat pada kalimat jangan engkau lupa, tanah pusaka, tanah air kita Indonesia.

\subsection{L agu "Timang-Timang Anakku Sayang"}

“Timang-Timang Anakku Sayang” yang dipopulerkan oleh Said Efendi, seorang komponis yang terkenal di era tahun 60-an sarat dengan doa dan harapan, serta kasih sayang orang tua, lagu tersebut adalah sebagai berikut

Timang-timang anakku sayang

Buah hati ayahanda seorang

Jangan marah dan jangan merajuk sayang

Tenanglah sayang dalam buaian

Betapakah hati takkan riang

Bila kau bergurau dan tertawa

Mogalah jauh dari marabahaya

Yang gembira sampai akhir masa

Setiap waktu ku berdoa

Pada Tuhan yang Mahakuasa

Jika kau sudah dewasa

Hidupmu bahagia sentosa

Timang-timang anakku sayang

Kasih hati permata ayahanda

Tidurlah tidur pejamkan mata sayang

Esok hari bermain kembali

Bait pertama nyanyian di atas mengungkapkan curahan hati seorang ayah ketika meninabobokan anaknya. Bait kedua dan ketiga mengungkapkan doa yang dipanjatkan orang tua kepada anaknya agar anaknya selalu bahagia, terhindar dari segala marabahaya, dan setelah dewasa hidup bahagia sejahtera. Bait keempat mengandung makna bahwa seorang anak perlu istirahat tidak bermain terus. 


\section{Simpulan}

Nyanyian kelonan merupakan salah satu bentuk nyanyian rakyat yang berfungsi, nyanyian kelonan yang berirama halus dan tenang sangat cocok dipakai sebagai media untuk menidurkan anak. Selain berfungsi sebagai pengantar tidur anak nyanyian kelonan mempunyai fungsi yang lain, yaitu sebagai sarana pendidikan karena lirik lagu-lagu nyanyian kelonan kebanyakan berisi doa dan nasihat. Sebagaimana yang terdapat dalam lirik lagu nyanyian kelonan "Lelo Ledhung", "Belaian Sayang", dan "TimangTimang Anakku Sayang”. Aspek pendidikan yang terdapat dalam ketiga lagu kelonan tersebut adalah: 1) ajaran agar selalau berdoa kepada Tuhan Yang Maha Esa, 2) ajaran budi pekerti, dan 3) cinta pada tanah air dan bangsa.

\section{Daftar Pustaka}

Al-Syaibani, O.M.A.1979. Filsafat Pendidikan Islam.(alih bahasa Hasan Langgulung). Jakarta: Bulan Bintang.

Danandjaja, James. 1994. Folklor Indonesia: Ilmu Gosip, Dongeng, dan lain-lain. Jakarta: Percetakan PT Temprint.

Jalaludin dan Abdullah Idi. 2007. Filsafat Pendidikan. Yogyakarta: Ar- Ruzz Media.

Muslich K.S., dkk. 2006. Konsep Moral dan Pendidikan dalam Manuskrip Keraton Yogyakarta. Yogyakarta: YKII - UIN Sunan Kalijaga.

Rapar, J.H. 1988. Filsafat Politik Aristoteles. Jakarta: Rajawali.

Sukmadinata, Nana Syaodih. 2005. Metode Penelitian Pendidikan. Bandung: Remaja Rosdakarya.

Teeuw, A. 1984. Sastra dan Ilmu Sastra: Pengantar Teori Sastra. Jakarta: Pustaka Jaya.

Waluyo, Hari.dkk. 1988. Terjemahan dan Kajian Wawacan Piwulang Istri. Jakarta: Departemen Pendidikan dan Kebudayaan Proyek Penelitian dan Pengkajian Kebudayaan Nusantara. 